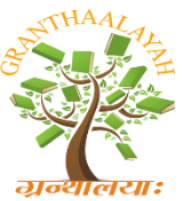

INTERNATIONAL JOURNAL OF RESEARCH GRANTHAALAYAH A knowledge Repository

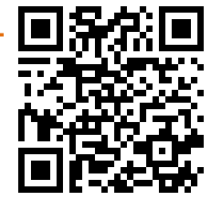

Science

\title{
COMPARATIVE STUDY BETWEEN VARIOUS PEDIATRICS DOSE CALCULATION FORMULAS: A CASE STUDY OF 12 YEARS CHILD FOR PARACETAMOL
}

\author{
Majid Khan *1, Muhammad Riaz ${ }^{2}$ \\ ${ }^{* 1}$ PharmD, Department of Pharmacy, Shaheed Benazir Bhutto University Sheringal Dir Upper \\ Khyber Pakhtun Khwa, Pakistan \\ ${ }^{2} \mathrm{PhD}$, Assistant Professor, Department of Pharmacy, Shaheed Benazir Bhutto University \\ Sheringal Dir Upper Khyber Pakhtun Khwa, Pakistan
}

\begin{abstract}
In this piece of study one case evaluated relevant to the dose calculation in which six formulas utilized for calculation of optimal doses and comparison between these formulas as well as beauty of all formulas. The different formulas used like on the basis of age includes Young rules, Dilling rules, Bastedo rules, Crowling, on the basis of weight Clark and Majid formula used and for Body Surface Area Mosteller formula utilized. The result of the current study purports for one patient of Paracetamol dose in which Young formula result is $250 \mathrm{mg}$, Dilling 300mg, Bastedo 250mg, Crowling $270.9 \mathrm{mg}$, on weight basis $278.5 \mathrm{mg}$ by Clark and Majid rule also 278.5 and $329 \mathrm{mg}$ by Mosteller Body Surface Area formula, the mean of the current result is $279.4 \mathrm{mg}$ that is nearest to weight formula considered as better and BSA formula shows $329 \mathrm{mg}$ that is in the category of therapeutic window because in British National Formulary Paracetamol dose ranges from 250$500 \mathrm{mg}$ and some authors reported Dilling rule is good due to simplicity and brevity. The current study concluded Dilling rule is the simplest one, weight base is nearest to average range and the most appropriate formula is BSA but slight lengthy in calculation. Dose calculation play crucial role in clinical condition of the patient and proper formula should be selected in order to get better therapeutic outcomes.
\end{abstract}

Keywords: Age Formula; Weight Formula; Clark Formula; Majid Formula; Mosteller Formula; Case Study.

Cite This Article: Majid Khan, and Muhammad Riaz. (2020). "COMPARATIVE STUDY BETWEEN VARIOUS PEDIATRICS DOSE CALCULATION FORMULAS: A CASE STUDY OF 12 YEARS CHILD FOR PARACETAMOL." International Journal of Research Granthaalayah, 8(3), 304-308. https://doi.org/10.29121/granthaalayah.v8.i3.2020.161. 


\section{Introduction}

According to "World Health Organization" the drug of choice in pyrexia is Paracetamol and "BNF" documented that the normal dose of Paracetamol for an adult is 500-1000mg three to four times and maximum dose is $4 \mathrm{~g}$ per day. The toxic dose for an adult is 10-15g / 24 hours (Twentythirty tablets) causes hepatoxicity and hepatocellular necrosis. That's why pediatric liver is not well developed and if damage from childhood will create great problems in future. In a similar way for 6-12 years child, the dose will be $250-500 \mathrm{mg}$ per 24 hours, in rest of dose $375 \mathrm{mg}$ will show better therapeutic outcome that is considered as therapeutic window, less than this range shows sub-therapeutic effect and more than therapeutic window shows toxic outcomes mean adverse responses [1] (Figure 1).

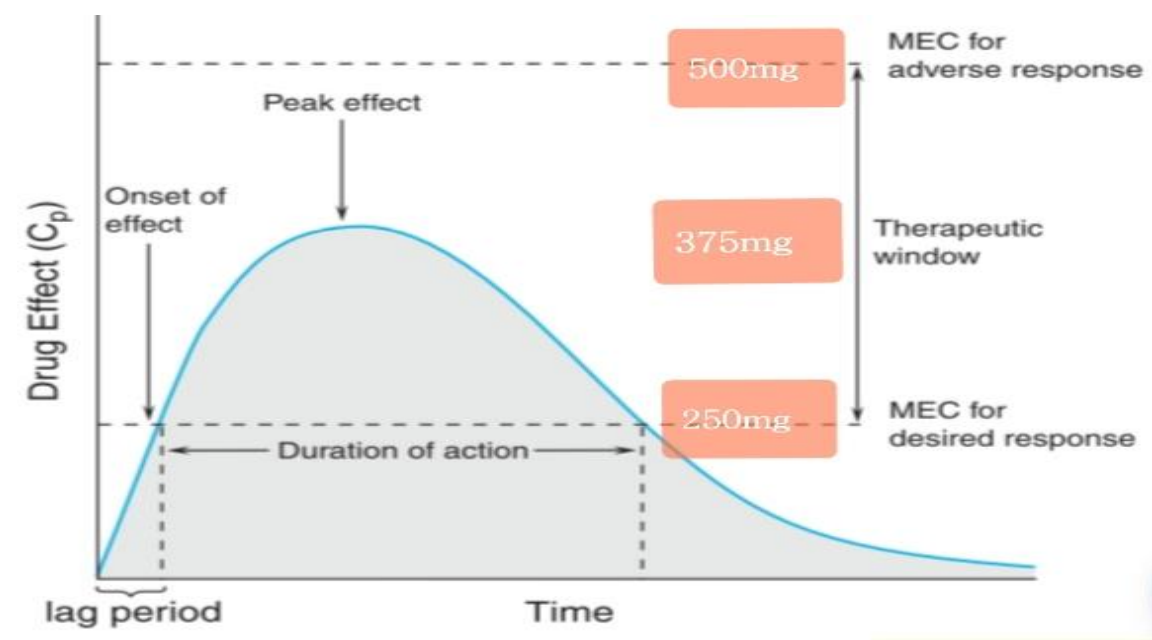

Figure 1: Normal dose for 12 years child for Paracetamol by "BNF" [1]

It plays crucial role in division and differentiation of dose of a drug for pediatrics, geriatrics or infants. In most of hospitals nowadays inappropriate doses reaches, due to lack of posological skills and knowledge. Thus, loss of both patient health and wealth on therapy and no actual therapeutic response achieved.

Various formulas supported in literature regarding pediatric dose calculation but due to controversy the selection of best one is crucial and required. Age, weight and BSA parameters considered for Pediatric dose calculation. The different formulas compared for 12 years child. The Pediatrics has different pharmacodynamic, physiological and pharmacokinetic properties as well as growth rate in comparison with adults. That's why dose calculation is crucial in order to achieve the optimal therapeutic outcomes to the patient. The drug concentration in the body is directly proportional to blood and plasma concentration and weight based formula for dose calculation is insufficient because it does not shows the actual blood and serum concentration [2]. It is well known that there is no acceptable, simple, easy and precise formula for dose calculation rather than complicated mathematics [3]. Nahat articulated that the selection of formulas for calculation of pediatric dose should be extensively careful [4].

Case study: A child of 12 years $(39 \mathrm{~kg})$ brought to the hospital with fever in temperature of $100^{\circ} \mathrm{C}$. The Physician prescribed Paracetamol 500mg syrup and said to the Pharmacist to calculate the 
dose for this patient. Compare the different formulas regarding the dose calculation and obtain the dose which is common, that formula will be future selected one. The formulas of different nature including age, body weight and surface areas, include:

Age is directly proportional to the dose of a drug increase with age except geriatrics, children (Pediatrics) requires fewer doses compared to adult, and old (Geriatrics), for infants best formula is Fried and Clark, clinically dose calculation for children has many formulas discovered by different scientists, about age, weight and surface area drugs formulas given under $[1,3,12]$.

\section{Methods}

Different formulas utilized like on the basis of age includes Young rules, Dilling rules, Bastedo, and Crowling rules, on the basis of weight Clark formula and Majid formula used and for Body Surface Area Mosteller formula utilized. Further detail is shown in (Table 1).

Table 1: Different formulas for child dose calculation

\begin{tabular}{|c|c|c|}
\hline Name & Formulas & Importance \\
\hline \multicolumn{3}{|l|}{ 1). Age base: } \\
\hline Young rules & Age in years / age $+12 \times$ Adult dose & Its result is standard in this study \\
\hline Dilling rules & Age in years $/ 20 \times$ A.D & $\begin{array}{l}\text { It is the simplest and easiest and } \\
\text { formula for child dose calculation }\end{array}$ \\
\hline Bastedo rules & Age $($ years $)+3 / 30 \times$ A.D & $\begin{array}{l}\text { It is one of the child dose calculation } \\
\text { formula }\end{array}$ \\
\hline Crowling rules & Age $($ years $)+1 / 24 \times$ A.D & $=$ \\
\hline \multicolumn{3}{|l|}{ 2). Weight base: } \\
\hline $\begin{array}{l}\text { Clark rules } \\
\text { Majid rules }\end{array}$ & $\begin{array}{l}\text { Weight }(\mathrm{kg}) / 70 \times \text { A.D } \\
\text { A.D/70 (Adult weight) } \times \text { weight } \\
(\mathrm{kg})\end{array}$ & $\begin{array}{l}\text { It is best when the calculation is not } \\
\text { possible from age } \\
=\end{array}$ \\
\hline \multicolumn{3}{|l|}{ 3). B.S.A base: } \\
\hline $\begin{array}{l}\text { B.S.A Mosteller } \\
\text { formula }\end{array}$ & $\begin{array}{l}\sqrt{\text { Weight }} \times \text { height } / 3600 \\
\text { Body Surface Area of child/ Adult } \\
\text { S.A }\left(1.73 \mathrm{~m}^{2}\right) \times \text { A.D }\end{array}$ & $\begin{array}{l}\text { It is best when calculation is not } \\
\text { possible by body weight }\end{array}$ \\
\hline
\end{tabular}

*A.D= Adult Dose, B.S.A= Body Surface Area [2, 5-12]

\section{Results}

The result for 12 years child is shown in (Table $2 \&$ Fig 2). The mean range of six formulas including on the basis of age, weight and Body Surface Area is $1678.4 \mathrm{mg}$. The result of the current study purports for one patient of Paracetamol dose in which Young rule result is $250 \mathrm{mg}$, Dilling $300 \mathrm{mg}$, Bastedo 250mg, Crowling $270.4 \mathrm{mg}$, on weight basis $278.5 \mathrm{mg}$ by Clark rule and similar by Majid rules and 329mg by Body Surface Area Mosteller rules, the mean of the current result is $279.4 \mathrm{mg}$ that is nearest to weight base formula that's why considered as better for this case. On other hand BSA Mosteller rules shows 329mg that is an ideal range for clinical condition of the patient and in the range recommended by BNF thus sufficient for patient better therapeutic outcome. 
Table 2: Result from Dose calculation formulas for 12 years child of Paracetamol

\begin{tabular}{|c|c|c|}
\hline Name & Results & $\begin{array}{l}\text { BNF } \\
\text { Standard }\end{array}$ \\
\hline \multicolumn{3}{|l|}{ 1). Age base: } \\
\hline Young rules & $12 / 12+12 \times 500=250 \mathrm{mg}$ & $250-500 \mathrm{mg}$ \\
\hline Dilling rules & $12 / 20 \times 500=300 \mathrm{mg}$ & $=$ \\
\hline Bastedo rules & $12+3 / 30 \times 500=250 \mathrm{mg}$ & $=$ \\
\hline Crowling rules & $12+1 / 24 \times 500=270.9 \mathrm{mg}$ & $=$ \\
\hline \multicolumn{3}{|l|}{ 2). Weight base: } \\
\hline $\begin{array}{l}\text { Clark rules } \\
\text { Majid rules }\end{array}$ & $\begin{array}{l}39 / 70 \times 500=278.5 \mathrm{mg} \\
500 / 70 \times 39=278.5 \mathrm{mg}\end{array}$ & $\begin{array}{l}= \\
=\end{array}$ \\
\hline \multicolumn{3}{|l|}{ 3). B.S.A base: } \\
\hline $\begin{array}{l}\text { B.S.A Mosteller } \\
\text { formula }\end{array}$ & $\begin{array}{l}\sqrt{ } 39 \times 120 / 3600 \\
1.140 / 1.73 \times 500=329 \mathrm{mg}\end{array}$ & $=$ \\
\hline Mean & $\begin{array}{l}250+300+250+270.9+278.5+278.5+329 / 7= \\
279.4 \mathrm{mg}\end{array}$ & $=$ \\
\hline
\end{tabular}

$* \mathrm{BNF}=$ British National Formulary, BSA= Body Surface Area.

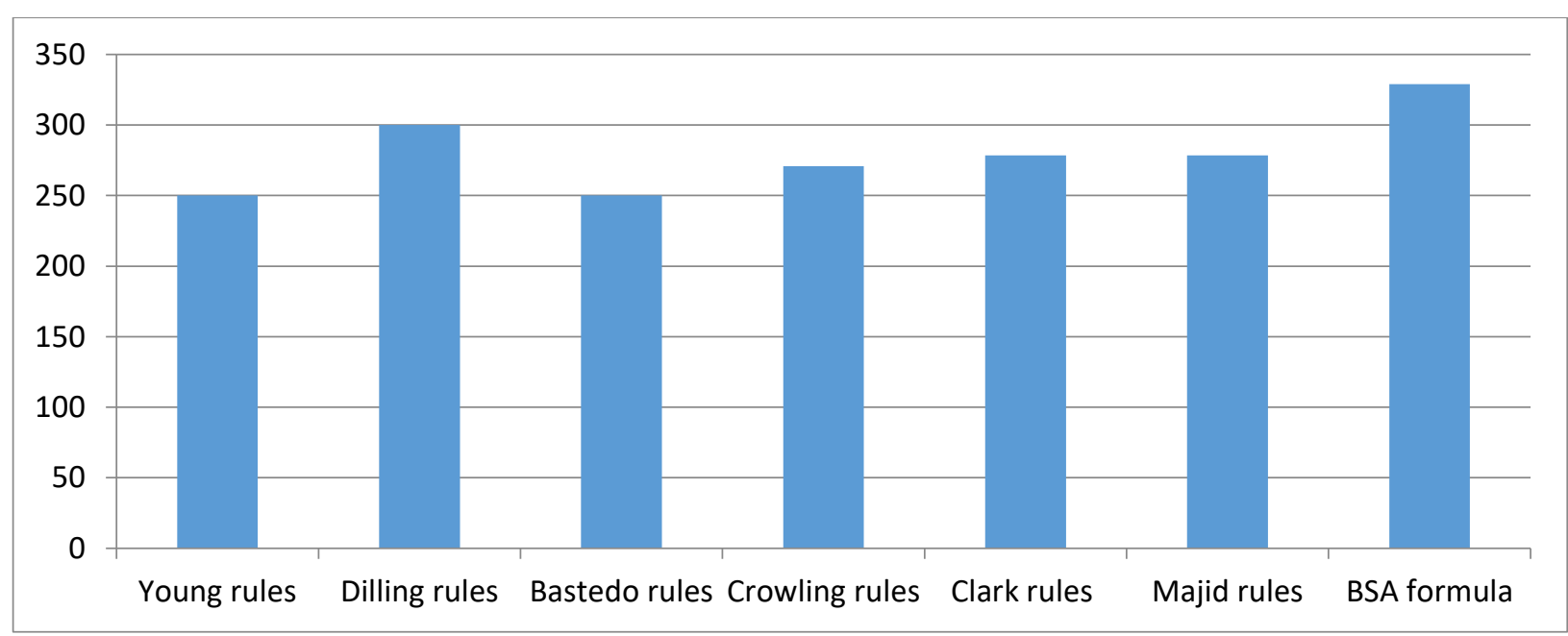

Figure 2: Comparison between dose calculation formulas for Paracetamol

\section{Discussions}

Paracetamol is high hepatotoxic in large doses [13]. Walson et al 1978, documented that BSA is better and corrected parameter than weight regarding pediatric dose calculation but slight difficult and time consuming in calculation [14]. Study conducted on Paracetamol by Elias et al in 2005, that BSA introduces the high dose than the recommended and proven to cause hepatotoxicity [2]. Study conducted by Robinson in 1970, as considered the weight and BSA favorable for pediatric dose calculation [15] in a similar way the Elias et al 2005 result is similar to this study but in our study three indicators utilized on the basis of age, weight and BSA. The Rodman conducted study on pediatric dose calculation in which he found the BSA gives higher the dose than weight indicator for dose calculation [16]. In current study the result by BSA formula is better 
recommended by BNF for 12 years child thus better applicable due to good therapeutic window. A.K Gupta documented that Dilling rule is simplest and easiest for child dose calculation [11].

\section{Conclusions and Recommendations}

Paracetamol is drug of choice in fever recommended by "World Health Organization". Thus, great care should be taken in case of Paracetamol dosage because if prescribe this in large doses causes hepatotoxicity and if on low dose will cause sub-therapeutic effect. There are different formulas utilized for pediatric dose calculation includes on age base (Young rule, Dilling rule, Bastedo rule, Crowling rule), on weight basis Clark and Majid rules and on body surface area Mosteller formula utilized. It is concluded from current study that Dilling rule is simplest one for child dose calculation, weight base calculation is an ideal range on the basis of average and BSA formula is good in therapeutic window but quite lengthy in calculation. This study is only limited to Paracetamol Posology. The authors suggest for multiple drugs and use these formulas for patients in order to optimize patient medication therapy.

\section{References}

[1] Gilmans, G., Manual of Pharmacology and Therapeutics McGraw Hill Medical, 2008.

[2] Gracieli Prado Elia, C.A., Ronaldo Célio Mariano, Comparative Study of Rules employed for calculation of Pediatric drug dosage J Appl Oral Sci, 2005. 13(2): 114-9.

[3] ME, L.J.S.-T., Calculation of drug dosage and body surface area of children. Brit J Anaesthesia, 1997: p. 601-5.

[4] MC., N., Advances in paediatric pharmacotherapy. J Clin Pharm Therap., 1992: 141-6.

[5] Singhal, K.C., Pharmacology laboratory manual, Pharmacy and Clinical Pharmacology, second edition. CBS publishers and distributors. 2: p. 6-7, 11.

[6] Tripathi, Tripathi essential of Medical Pharmacology, chapter 5 Pharmacotherapy, Clinical Pharmacology and Drug Development, edition 7th. Jaypee publisher, 2013.

[7] S.Reiss, G.H.B., Lange Q\&A, Pharmacy. McGraw Hill Medical, 2011

[8] VN Sharma, t.e., Essential of Medical Pharmacology. 2007.

[9] Remington: The Science and Practice of Pharmacy 22nd edition. Royal Pharmaceutical Press Society, 2013.

[10] Dale, R.a., "Pharmacology" international 5th edition. Elsevier science Churchill Livingstone., 2003.

[11] Gupta, A.K., Introduction to Pharmaceutics-II, 4th edition, CBS publishers and distributors, 2005 p. 52.

[12] Majid Khan, Asaf Khan, Concepts of General Pharmacology and Clinical Approaches, Lambert Academic Publisher LAP, 2020, ISBN 978-620-2-51152-0

[13] BNF Sep-58, bnf.org. Pharmaceutical Press, BMJ group, 2009.

[14] G., U., Pediatric clinical pharmacology: a practical review. Amer J Dis Child., 1978. 132:1: p. 1025-32.

[15] VS., R.G.W., Dosage and method of administration of drugs in childhood. Practitioner. 1970; 204:p. 5-13.

[16] JH, R., Pharmacokinetic variability in the adolescent: implications of body size and organ function for dosage regimen design. J Adolesc Health., 1994. 15: p. 654-62.

*Corresponding author.

E-mail address: majidkhanpiran@gmail.com 